Economic predictors of child maltreatment in an Australian population-based birth cohort

This document is the preprint and accepted manuscript for an article appearing in Children and Youth Services Review and available at http://dx.doi.org/10.1016/j.childyouth.2016.10.012 • (C) 2016. This manuscript version is made available under the CC-BY-NC-ND 4.0 license http://creativecommons.org/licenses/by-nc-nd/4.0/. When citing, please refer to the published version:

Doidge, James C., Darryl J. Higgins, Paul Delfabbro, Ben Edwards, Jown W. Toumbourou, Suzanne Vassallo and L Segal. 2016. Economic Predictors of Child Maltreatment in an Australian Population-Based Birth Cohort. Children and Youth Services Review. Published online 17 October 2016.

http://dx.doi.org/10.1016/j.childyouth.2016.10.012

Authors: $\quad$ James C Doidge ${ }^{\mathrm{a}, \mathrm{b}}$, Daryl J Higgins ${ }^{\mathrm{c}, \mathrm{d}}$, Paul Delfabbro ${ }^{\mathrm{e}}$, Ben Edwards ${ }^{\mathrm{c}}$, Suzanne Vassallo $^{c}$, John W Toumbourou ${ }^{\mathrm{f}}$, Leonie Segal ${ }^{\mathrm{b}}$

Affiliations: $\quad{ }^{a}$ Administrative Data Research Centre England, University College London

${ }^{\mathrm{b}}$ Centre for Population Health Research, University of South Australia, Adelaide, Australia

${ }^{c}$ Australian Institute of Family Studies, Melbourne, Australia

${ }^{\mathrm{d}}$ Faculty of Medicine, Dentistry and Health Sciences, University of Melbourne, Australia

${ }^{\mathrm{e}}$ School of Psychology, University of Adelaide, Australia

${ }^{\mathrm{f}}$ Deakin University, Melbourne, Australia

Correspondence: James.C.Doidge@gmail.com 


\begin{abstract}
A correlation between socioeconomic disadvantage and child maltreatment has long been observed, but the drivers of this association are poorly understood. We sought to estimate the effects of economic factors on risk of child maltreatment after adjusting for other known influences using the Australian Temperament Project, a population-based birth cohort of 2443 individuals and their parents. We used logistic regression to estimate associations of childhood economic factors (parental education, occupation, and unemployment; type of housing; and retrospective perception of poverty) with retrospective reports of perceived child maltreatment (physical abuse, sexual abuse, emotional abuse, neglect, and witnessing of domestic violence), controlling for demographic factors, parental mental health and substance use, and child health. We then used these estimates to approximate the proportions of child maltreatment-population attributable fractions - that are theoretically preventable by addressing childhood economic disadvantage. Economic factors were associated with all types of child maltreatment. For the most part, these associations diminished only partially when controlling for noneconomic confounders, supporting hypotheses of causal relationships. Jointly, economic factors were significant predictors of physical abuse, sexual abuse, and witnessing of domestic violence but not of emotional abuse or neglect. Retrospective perceptions of childhood poverty were, in particular, strongly associated with most forms of child maltreatment but not with sexual abuse after accounting for other economic factors. We estimated that $27 \%$ of all child maltreatment was jointly attributable to economic factors. These findings suggest that strategies that reduce economic disadvantage are likely to hold significant potential to reduce the prevalence of child maltreatment.

Keywords: child maltreatment; child abuse and neglect; poverty; socioeconomic disadvantage; social determinants; risk factors
\end{abstract}




\section{Economic predictors of child maltreatment in an Australian population-based birth cohort}

\section{Introduction}

The association between child maltreatment and poverty has been well-established in the literature, despite initial concerns of detection bias and victim-blaming (Pelton, 1978; Zellman, 1992). The reasons for the association, however, are not well-understood (Berger \& Waldfogel, 2011). In their recent review of the literature on poverty and child maltreatment, Drake and Jonson-Reid (2014) identified many likely contributors to the relationship between poverty and maltreatment but noted that the causality of the relationship has a particularly poor underpinning in both theory and empirical research. By modelling the temporal contribution of potential causal influences, the present study aims to provide empirical estimates of the causal contribution of parent- and family-level economic factors to the risk of child maltreatment.

\subsection{Risk factors for child maltreatment}

In reviews of the risk and protective factors for child maltreatment, researchers have identified a range of social and environmental factors, many of which center on socioeconomic disadvantage (Brown, Cohen, Johnson, \& Salzinger, 1998; Stith et al., 2009; U.S. Department of Health and Human Services, 2015). Factors identified as being important include parent-level factors (e.g., low education and income) and broader social or structural factors such as income inadequacy, unemployment levels, social isolation, inadequate housing and homelessness, and poor access to resources (child care, welfare services, schools, etc.), exposure to racism or discrimination, and stressful life events (Lamont \& Price-Robertson, 2013). The largest group of risk factors associated with the occurrence of abuse and neglect relate to parental characteristics that prevent or interfere with good parenting skills, appropriate monitoring, and affective responses to children and their changing developmental needs. 
Such social and economic factors are, however, highly interrelated conceptually and empirically. One distinction that can be drawn is between factors that are fixed (age, race/ethnicity, and gender, etc.—-factors that might be considered "demographic"), and factors that may be more amenable to change (education, unemployment, poverty, etc.). In the subsequent analysis, parental education, occupation, unemployment, housing, and poverty are considered jointly as potentially modifiable factors contributing to economic disadvantage. A further distinction is offered, however, between poverty - perhaps a purer measure of economic disadvantage - and the remaining indicators, which are more closely related to social status and arguably more intrinsic characteristics of the parents than are household wealth or income.

Poverty has been postulated to affect child maltreatment through a range of mechanisms, including limiting parental capacity to provide for the needs of their children (food, shelter, medical care, etc.), increasing parental stress, reducing incentives for parents to invest their time and money in child-rearing, and reducing alternatives for discipline (Berger \& Waldfogel, 2011). Whether and how much parents work may directly influence the amount of time that parents spend with children and thus the opportunity for exposure to poor parenting of any type, and may greatly increase the psychological stress that parents are exposed to. Conger and Donnellan (2007) offer a theoretical framework through which socioeconomic disadvantage may influence parenting behavior and child well-being. Family economic pressures act as stressors that increase parental conflict and inhibit nurturing and involved parenting and increases the propensity for harsh parenting behavior in their model. If economic factors contribute to destabilization of parental relationships or increased rates of parenthood outside of stable relationships, this would also increase the opportunity for children to be maltreated by their parents' associates (boyfriends, step-parents, etc.). 


\subsection{Questions of causality and the potential outcomes framework}

Estimating the causal effect of economic factors on child maltreatment is important because it provides guidance regarding how best to intervene. If the relationship between economic factors and child maltreatment is not causal, then addressing economic disadvantage will have little effect in terms of preventing child maltreatment. On the other hand, if the relationship between economic factors and child maltreatment is causal, then intervention to address economic disadvantage is likely to reduce the prevalence of child maltreatment and policies that increase economic disparities may exacerbate the problem.

In this analysis, we adopt an epidemiological approach to causal inference that is rooted in the potential outcomes framework (Glass, Goodman, Hernán, \& Samet, 2013). This approach focuses on the differences in potential outcomes (in this case, child maltreatment) that would occur under scenarios that differ only with respect to the distributions of certain risk factors (economic disadvantage). If changing only the risk factor will change the outcome, then the relationship can be said to be causal. However, with outcomes such as child maltreatment and risk factors like economic disadvantage, true experiments can be difficult to construct and we must often rely on observational data to test the causality of these relationships or estimate their strength.

The main limitation of observational data as compared with experimental data is that there are often differences between people that are associated with both the exposure and outcome in question. Such differences confound the observed association, making it appear weaker or stronger than would result from a causal effect alone. Addressing confounding is therefore central to causal inference in observational data (Glass et al., 2013).

For something to confound the relationship between economic disadvantage and child maltreatment, it must either cause or have a common cause with both. As such, confounders are 
mostly limited to demographic factors (family size and structure, ethnicity, parental age, etc.) and parental characteristics (particularly mental health, substance use, and parental history of child maltreatment). Child health problems may also affect the risk of maltreatment while placing additional economic pressures on parents (Font \& Berger, 2015) but the relationship between child health and maltreatment is likely to be bidirectional. Domestic violence is a wellestablished risk factor for child maltreatment that is associated with economic disadvantage, but it can itself be considered a form of psychological or emotional abuse (James, 1994; Kitzmann, Gaylord, Holt, \& Kenny, 2003) and this is how we conceptualize it here.

\subsection{Empirical evidence on the economic causes of child maltreatment}

While experimental studies of the effects of economic factors on risk of child maltreatment are rare, occasional opportunities arise in the course of changes to things like income support programs. New programs or changes may be rolled out incrementally, producing experimental conditions in which direct comparison can be made between groups receiving the new and old services. Sometimes, programs can even be rolled out in a randomized manner to ensure comparability of the treatment groups and facilitate evaluation of the program. This was the case in the study by Cancian, Yang, and Slack (2013), which found that an exogenous increase in the proportion of child support payments that was distributed to resident parents, thus increasing their income, was associated with decreased screened-in child protection notifications regarding their children.

A related form of 'natural' or 'historical' experiment can occur when exogenous factors (factors external to the parent-child relationship) are suddenly changed or interrupted. Population-level economic factors have few theoretical pathways through which their relationship to child maltreatment can be confounded, reducing the need to collect or model data 
on large numbers of variables simultaneously. For example, Wildeman and Fallesen (2016-this issue) found that a substantial reduction in a specific type of Danish welfare payment increased risk of out-of-home placement by 25\%. Similarly, Schneider, Waldfogel, and Brooks-Gunn (2016 - this issue) linked macroeconomic indicators of the Great Recession (the American experience of the Global Financial Crisis) to measures of behavioral approximations of physical abuse and neglect taken over the corresponding period in a population-based birth cohort. They found that there were direct effects of the Great Recession on risk of behaviorally approximated physical abuse but no effects or weak protective effects on risk of behaviorally approximated neglect. At the same time, using state-level child protective services data from the U.S., Raissian and Bullinger (2016 - this issue) found that increases to the state minimum wage reduced reports of child neglect.

Outside of true and 'natural' experiments, observational investigation of the causes of child maltreatment is generally restricted by the limited availability of large-scale epidemiological data sets that contain a sufficient range of postulated risk factors to be modelled simultaneously (Munro, Taylor, \& Bradbury-Jones, 2013). As most of the causes of child maltreatment operate at or through the level of the parents, data collection must span multiple generations and long periods of time. There are few prospective cohort studies that collect such broad information over these periods. In the Mater-University of Queensland Cohort Study, Martin et al. (2011) reported an analysis of the effects of maternal economic and noneconomic risk factors (measured early in the life of their offspring) on sexual abuse as reported by offspring in early adulthood. Maternal education recorded during pregnancy, and family income (recorded when the child was 6 months old), were associated with penetrative but not nonpenetrative sexual abuse. Other risk factors included in multivariate analyses included maternal 
age, marital status, smoking and alcohol consumption, mental health, and attitudes towards the baby. They found that most of the correlation between family income and penetrative sexual abuse was accounted for by other risk factors, while the association with maternal education changed little, which suggested some causal role for this factor. Using data from the National Longitudinal Survey of Youth, Berger $(2004,2007)$ found that higher levels of income were independently associated with improved parenting practices, particularly in families that had experienced parental separation. Using data from the National Longitudinal Study of Adolescent to Adult Health (Add Health), Hussey, Chang, and Kotch (2006) observed associations between family income and neglect and sexual abuse, and between parental education and physical neglect and physical abuse, that were robust to adjustment for other sociodemographic variables. In the Christchurch Health and Development Study, family income and family living standards were strongly associated with risk of physical abuse, but were dropped from automated variable selection models in multivariate analyses, while associations with maternal education and parental occupation were not statistically significant (Woodward \& Fergusson, 2002). Most other large cohorts with data on child maltreatment have either not collected detailed information on economic risk factors (e.g., the Adverse Childhood Experiences Study) or have not explored the relationship using multivariate analysis (e.g., Brown et al., 1998).

Trials and evaluations of family support programs can also sometimes provide data that are useful for analyzing the causes of child maltreatment. Using child maltreatment data collected by nurse home visitors in a trial of a support program for families with preterm, low birth weight infants, Berger and Brooks-Gunn (2005) found that socioeconomic factors predicted risk of child maltreatment after controlling for a rich set of potential confounders, including parental knowledge and behaviors that were themselves closely related to child maltreatment. 
Studies using linked administrative data can provide some insights, but usually only limited information will be available about risk factors. O'Donnell et al. (2010) reported one of the best examples of administrative data research, which involved linking child protection data to a birth registry and perinatal data collection. The study obtained information about family demographics and child health, linked to hospital and mental health services, to obtain information about parental mental health, substance use, and assault-related injuries. However, information about economic factors in their study was limited to a single measure of the relative socioeconomic disadvantage in the area of residence at the time of the child's birth. They found that half of the correlation between area-level relative socioeconomic disadvantage and substantiated child maltreatment in non-Indigenous Australians was due to confounding by other factors, leaving half to be due to causal effects or residual (unmeasured) confounding. After adjustment for confounding, the most disadvantaged $8 \%$ (according to the area-based measure of socioeconomic disadvantage) were 5.4 times as likely to have substantiated child maltreatment compared with the least disadvantaged $8 \%$. In a similar analysis of data from the U.S., Lee and Goerge (1999) found that the association between community level of poverty and alleged child maltreatment was essentially unaffected by adjustment for parental age, ethnicity, birth order, child gender, or region of birth, although these estimates may be biased by a larger number of omitted variables. Berger et al. (2015) linked administrative data on home foreclosures to child protection data, and observed increased risks of child protection involvement in the periods immediately before and after home foreclosure.

Berger (2005) reported an analysis of cross-sectional data from the (American) 1985 National Family Violence Study, which included an extensive range of parent- and state-level risk factors for child maltreatment and parental report of violence towards children. He found 
that economic risk factors (family income, low parental education, state unemployment rate, and state urbanization) had significant positive effects on rates of physical abuse, after adjusting for other factors (including demographics, parental mental health and substance use, parental exposure to domestic violence as adults or children, and parental experience of physical abuse). These effects applied in single-parent families but not in two-parent families. However, one of the main limitations of such cross-sectional studies is the lack of temporality in the measures of risk and effect.

\subsection{Overview of the present study}

This study attempts to estimate the effects of economic disadvantage on different forms of child abuse and neglect in a population-based birth cohort, the Australian Temperament Project (ATP). The ATP has prospectively collected data on parent- or family-level economic factors, social factors, mental health and substance use, and child health and temperament and retrospectively self-reported exposure to child maltreatment. The robustness of economic factors to confounding by other risk factors is assessed using multivariate logistic regressions. The contribution of economic factors to the prevalence of child maltreatment is assessed using population attributable fractions (PAF). Attributable risk analysis compares different scenarios: the present distributions of risk factors, and hypothetical alternatives in which certain risk factors have been removed or had their distributions altered. In the present context, a PAF provides an estimate of the proportion of child maltreatment that would be avoided if policy or intervention were to reduce economic disadvantage, assuming that the estimated coefficients of regression models are causal in nature, an admittedly tenuous assumption. 


\section{Data}

\subsection{Participants}

The ATP has surveyed the families of 2443 children, over 15 waves of data collection since enrollment at the age of 4-8 months in 1983 (baseline). Since baseline, the cohort has been expanded to include some additional twins who were excluded from this analysis. Methods pertaining to the collection of data and sample characteristics have been previously reported (Prior, Sanson, Smart, \& Oberklaid, 2000; Sanson \& Oberklaid, 1985; Vassallo \& Sanson, 2013). Sampling was stratified at the local government area to represent the Australian state of Victoria and the distribution of demographic characteristics was consistent with census data (Sanson \& Oberklaid, 1985). Approximately half (48.1\%) of respondents were female, one quarter $(22.2 \%)$ had at least one parent who was born in a non-English-speaking country. At baseline, about one in twenty parents (2.5\% of fathers and $7.3 \%$ of mothers) were aged less than 22 years and one quarter (23.9\% of mothers and $29.2 \%$ of fathers) were less than tertiaryeducated.

\subsection{Variables}

Risk factors for child maltreatment were derived from prospective survey of parents across cohort ages $0-16$ years (Waves 1-11) and retrospective survey of cohort members at age 23-24 years (Wave 14). Indicators of child maltreatment were derived from retrospective survey of cohort members at 23-24 years (Wave 14). Variables are described below with further details about question wording for key variables provided in Table 1.

<INSERT TABLE 1 ABOUT HERE> 


\subsubsection{Child maltreatment}

Indicators of child maltreatment included self-reported retrospective perceptions of emotional abuse, physical abuse, sexual abuse, neglect, and exposure to domestic violence (considered a form of psychological abuse). Physical abuse was consistent with a definition based on effects lasting until the next day, so excluded low-intensity physical discipline (physical treatment without effects lasting until the next day was reported by $33.5 \%$ of respondents). Sexual abuse included any attempted or enacted sexual advances from family members and any nonconsensual sexual activity before the age of 16 . This definition therefore encompasses some forms of sexual assault that would not normally be classified as abuse. The definition was adopted based on the available questions so as not to exclude sexual abuse by people who may not be considered family members of the respondents (friends or partners of caregivers, teachers, priests, etc.). A sensitivity analysis was conducted in which the definition was separated according to responses to the two contributing questions. Two levels of emotional abuse are presented, both based on the same item but one representing high-intensity ("very true") and one low-intensity ("somewhat true"). Neglectful parenting was a subjective assessment of the cohort members and witnessing of domestic violence was also determined from their self-report.

The definitions of maltreatment that are implied by this phrasing of questions and coding of responses are consistent with the five categories of child abuse and neglect identified by the Australian Institute of Family Studies (Goldsworthy, 2015). The legal definitions prescribed for use by child protection systems differ by state or territory (for an overview, see Scott, 2014). They generally cover the same types of maltreatment but focus on the need for protective intervention, as indicated by current risk and the capacities and availability of caregivers. For example, sexual abuse that occurs outside of the family home may be unlikely to meet statutory thresholds for intervention unless there is ongoing risk in which caregivers are implicated (e.g., 
through supervisory neglect). Similarly, substantiations of past maltreatment do not meet the evidentiary thresholds for a child in need of protection in all states and territories. Our implied definitions of emotional abuse, physical abuse, and sexual abuse are reasonably consistent with legal definitions in all states and territories. Exposure to domestic violence is specified as a form of maltreatment in the legislation of Tasmania and the Northern Territory at least, and may in practice be implemented as such in other regions. Legal definitions for neglect generally focus on physical neglect (lack of provision of adequate housing, food, medical care, etc.), with emotional neglect usually encompassed within emotional or psychological maltreatment. Our implied definition of neglect, for which the available question wording was very subjective, is more open to inconsistency with official and legal definitions.

\subsubsection{Economic factors}

Economic factors included the occupation and highest completed level of education for mothers and fathers at baseline, the highest quality of housing reported by Wave 6 (7-8 years), unemployment by mothers or fathers at five waves during childhood, and the cohort member's retrospective perception of poverty while growing up, recorded at 23-24 years (Wave 14). To facilitate inclusion of a large number of variables in regression models and to minimize the distributional assumptions of imputation models (which are described further in section 3), all risk factors were collapsed into binary indicators. To select appropriate thresholds for this, associations between risk factors and indicators of child maltreatment were plotted to identify cut-points that maximized discrimination of overall risk of child maltreatment. The raw associations that guided selection of these thresholds are illustrated in Appendix A. 


\subsubsection{Parental education and occupation}

Based on these graphs, parental education was collapsed into 'at least technical diploma' (tertiary degree) versus 'less than technical diploma' (no tertiary degree). Parental occupation was collapsed into 'professional or managerial' versus other. As all risk factors had the high-risk level coded as positive (such that an odds ratio of greater than 1.00 conveys risk), the dummy variables used were 'mother/father less than tertiary educated at baseline' and 'mother/father less than professional/managerial at baseline." As these were more common than tertiary education and professional/managerial occupations, they should not be interpreted as 'low' education or occupation and are perhaps better thought of as reverse-coded protective effects of 'high' education and occupation.

\subsubsection{Housing}

With respect to housing, the main difference was between owner-occupied homes and other types of accommodation, so housing was collapsed into a dummy indicating 'lack of homeownership by 7-8 years.' There was little difference in the risk of child maltreatment between participants whose parents reported none or only a single period of unemployment, but risk increased substantially beyond that so a binary variable was created distinguishing multiple points of unemployment from less than two. With respect to retrospective perception of poverty while growing up, risk increased only slightly in people who were 'uncertain' but then substantially in people who selected 'somewhat true' or 'very true,' so a binary variable was created to distinguish these latter two from the remainder.

\subsubsection{Potential confounders}

Potential confounders included demographic variables (parental age $<22$ years at baseline, parental immigration from a non-English speaking country at baseline, parental 
separation during childhood, more than four children in family); indicators of parental mental health and substance use (current or past parental smoking measured when the child was 13-14 years [Wave 10] or 17-18 years [Wave 12]; mother and father high-level drinking or ex-drinker at 13-14 years or 17-18 years [Waves 10 and 12], and cohort member's retrospective report of parental substance use problems and parental mental illness while growing up); and indicators of child health (low birth weight, having two or more investigated health problems by age 3 [Wave 3], and cohort member's retrospective self-report of cognitive or behavioral problems and physical health problems while growing up). Gender of the cohort member was not included as a control variable in the main analyses because of its lack of plausible connection to economic disadvantage (which was supported by a lack of observed association) and therefore lack of potential to confound the relationship between economic disadvantage and maltreatment. Gender was later included as a sensitivity analysis.

\subsection{Missing data}

Of the original cohort of 2443 infants, investigators still had contact details for 1490 at 23-24 years (Wave 14), and 980 responses were received (excluding 20 responses from twins enrolled post-baseline). For the 26 variables that were the focus of our analysis, only one (gender) was available for every cohort member, and three quarters (77.6\%) of participants had at least some missing data. The characteristics of participants with complete data differed from the cohort at baseline with respect to various socioeconomic characteristics (Table 2) so the first step in the analysis was to address this issue.

\section{Analysis}

Substantial amounts of missing data are ubiquitous in cohort studies with extended follow-up such as the ATP. Of particular concern in this instance was the relationship between 
child maltreatment, loss to follow-up, and nonresponse. When questions about child maltreatment were asked in early adulthood, about two-fifths of the cohort had been lost to follow-up and another fifth did not return the questionnaire. Exploratory analyses indicated associations between child maltreatment and the probability of data being missing, for nearly every variable (Doidge, Edwards, Higgins, \& Segal, 2015).

To maximize the plausibility of our assumptions with respect to missing data in this context, we implemented an extended form multiple imputation: responsiveness-informed multiple imputation (RMI; Doidge, 2016). This approach utilized a large number of auxiliary variables, including measures of responsiveness, in imputation models. Recent simulation studies have shown that, when used as auxiliary variables, measures of responsiveness (such as the proportion of waves and items completed by parents and cohort members) can greatly improve the performance of techniques for addressing missing data in longitudinal studies with many time points of data collection (Doidge, 2016). Auxiliary variables are correlates of either the variables containing missing data or of missingness itself, which can provide additional information about missing data, thereby making the assumptions underlying an analysis more plausible.

In total, 100 auxiliary variables were used, although many were included to support future analyses and not all variables could be included in each model. The auxiliary variables were all hypothesized correlates of child maltreatment; other risk factors or outcomes of it. Each imputation model included at least indicators of child maltreatment, parental mental illness, parental substance use, cohort gender, and indicators of parent- and cohort-responsiveness. As many other closely related auxiliary variables were added to each imputation model, as could be supported without generating computation errors. Priority was given to economic factors and to 
variables from within the same domain as the variable being imputed. Further details about imputation models and auxiliary variables are available from the corresponding author and have been submitted for publication (Doidge et al., 2015). Each variable containing missing values was imputed by logistic or ordered logistic regression, augmented in cases of perfect prediction (White, Daniel, \& Royston, 2010). Twenty imputation sets were generated using chained equations (fully conditional specification; van Buuren, 2007).

\section{<INSERT TABLE 2 ABOUT HERE>}

Multiple imputation effectively reduced all differences that were observed in baseline characteristics between the whole cohort and complete cases (Table 2). Multiple imputation substantially increased the estimated prevalence of retrospectively reported child maltreatment, and the estimated prevalence of economic risk factors that were measured during follow-up: retrospective perception of poverty, recurrent/protracted parental unemployment, and lack of homeownership.

For the substantive analysis, a series of multivariate logistic regressions were used to assess the degree to which the association between economic factors and child maltreatment was explained by confounding. For each classification of maltreatment (any, high-intensity emotional abuse, low-intensity emotional abuse, neglect, physical abuse, sexual abuse, and witnessing of domestic violence), three progressive models included an increasing number of potential confounders. The final models included covariates with potential endogeneity to child maltreatment (variables that are potentially caused by child maltreatment as well as risk factors for it: parental separation and child health). To explore the differentiation between poverty and other economic factors, two variations of each model were run: including the retrospective measures of poverty (model groups $1 \mathrm{a}, 2 \mathrm{a}$, and $3 \mathrm{a}$ ), or excluding these measures (model groups 
1, 2, and 3). In model 3, only prospective measures of child health were included, while model 3a added retrospective measures of child health. This produced a total of 48 models (8 outcomes x 3 models x 2 variations).

Finally, using the conditional odds ratios from regression model groups 3 and $3 \mathrm{a}$, and the distributions of risk factors in the study sample (after multiple imputation), we estimated PAFthe proportion of child maltreatment that might have been prevented by removing economic risk factors. Attributable fractions were estimated using the punaf package for Stata (Newson, 2013; modified for use with multiply imputed data), which implements the method described by Greenland and Drescher (1993). In essence, the method estimates the prevalence of child maltreatment that would occur if the whole sample were to have the favorable level of the risk factor (e.g. tertiary-educated parents, low parental unemployment, etc.), but the observed distribution of other covariates (i.e., only the risk factor is changed). As the ATP sample represents the population of Victoria, Australia, the difference between the observed and estimated prevalence is the estimated attributable fraction for the Victorian population. All analyses were conducted using Stata 12 (StataCorp, Texas).

\section{Results}

\subsection{Descriptive statistics}

Participant characteristics are presented in Table 2. After multiple imputation, reported exposure to child maltreatment ranged from $6.2 \%$ (emotional abuse = "very true") to $18.9 \%$ (emotional abuse = "somewhat true") and was $37.2 \%$ for any maltreatment. Of those who reported maltreatment, $44.4 \%$ reported multiple types. Among those who reported witnessing domestic violence, $82.1 \%$ reported at least one other form of maltreatment. The prevalence of 
economic risk factors varied greatly (from $9.3 \%$ to $76.3 \%$ ), reflecting the data-informed approach to their coding.

It is useful to consider these estimates in the broader Australian context. In Australia, as elsewhere, estimates for the prevalence of child maltreatment vary wildly depending on the definitions used, source of information, and method of population-sampling (Price-Robertson, Bromfield, \& Vassallo, 2010). During 2013 to 2014, 3.8\% of Australian children were the subject of a child protection notification, $1.9 \%$ were the subject of an investigation, $0.8 \%$ had their maltreatment substantiated, and 1.0\% spent time in out-of-home care (largely foster and kinship care; Australian Institute of Health and Welfare, 2015). Only a single study of the cumulative incidence of child protection involvement across childhood is available, which found that cumulative risk of notification to child protection services in South Australia were $23 \%$ for children born in 1991 and cumulative substantiations were 6\% (Delfabbro, Hirte, Rogers, \& Wilson, 2010a). Both of these statistics appear to have been increasing dramatically (at least double) over recent years, and Aboriginals are grossly overrepresented (Delfabbro, Hirte, Rogers, \& Wilson, 2010b). Estimates from self-reported exposure to emotional abuse in Australia range from $5.8 \%$ to $11.3 \%$ (two estimates only, other than from the ATP), from $1.6 \%$ to $12.2 \%$ for neglect (two other estimates only), from $5.0 \%$ to $18.0 \%$ for physical abuse, from $10.5 \%$ to $42.0 \%$ for sexual abuse, and from $5.5 \%$ to $23.0 \%$ for witnessing of domestic violence (Price-Robertson et al., 2010). Thus, our estimates for low-intensity emotional abuse are larger than other published estimates (which likely reflects different thresholds), and our estimate of exposure to domestic violence is smaller, while other types of maltreatment fall within the range of published estimates. 
We also created a count variable, representing the number of economic risk factors reported by each respondent in order to examine the bivariate associations between child maltreatment and cumulative economic disadvantage and the findings are summarized in Table

3. The dose-response relationship between economic disadvantage and child maltreatment increased sharply beyond four risk factors, with dramatically higher prevalence of child maltreatment in the most disadvantaged group ( 7 risk factors) compared with the least disadvantaged group (0 risk factors).

\section{<INSERT TABLE 3 ABOUT HERE>}

\subsection{Regression results}

Unadjusted odds ratios for different types of child maltreatment with respect to collapsed economic factors are provided in the first two columns of Error! Reference source not found.. The first column presents results from complete case analyses, the second from analyses of multiply imputed data. All economic factors were strongly associated with sexual abuse, witnessing of domestic violence, and overall risk of any child maltreatment. Multiple points of parental unemployment and retrospective perception of poverty were strongly associated with all forms of child maltreatment. Most associations weakened somewhat when comparing the multiply imputed estimates with the raw (complete case) estimates, but the differences were not as strong as the differences seen in prevalence estimates and none were statistically significant.

\section{$<$ INSERT TABLE 4 ABOUT HERE >}

In the first set of multiple regression analyses, retrospective perception of poverty, recurrent or protracted parental unemployment, and lack of homeownership were the economic factors most strongly related to child maltreatment (Table 3, model groups 1 and 1a). However, the estimated odds of sexual abuse with respect to retrospective perceptions of poverty reduced 
more substantially and became nonsignificant when other economic factors were controlled.

Other notable differences in the pattern of economic risk factors across specific types of maltreatment were that less than professional/managerial paternal occupation independently predicted physical abuse, and less than tertiary maternal education independently predicted lowintensity emotional abuse.

After this initial adjustment, controlling for early-life social factors and parental mental health and substance use (model groups 2 and $2 \mathrm{a}$ ) or all social factors, parental mental health and child health (model groups 3 and 3a) diminished most effect estimates only slightly. The conditional odds of sexual abuse with respect to retrospective perceptions of poverty diminished

close to 1.00. Inclusion of retrospective measures of poverty (model groups 1, 2, and 3 compared with 1a, 2a, and 3a) made little difference to the coefficients of parental education and occupation, but moderately diminished the coefficients of housing and parental unemployment, indicating a greater degree of overlap between these three variables.

Jointly, economic factors were significant predictors of physical abuse, sexual abuse, and witnessing domestic violence, but not of emotional abuse or neglect. Retrospective perception of poverty was a consistently strong predictor of all types of maltreatment except for sexual abuse, for which its coefficient diminished more substantially as control variables were added to the models. Recurrent or protracted parental unemployment was most strongly implicated in domestic violence and sexual abuse, while paternal occupation was strongly implicated in physical abuse.

\subsection{Population attributable fractions}

Estimates for the proportion of child maltreatment attributable to economic disadvantage are presented in Error! Reference source not found.. In line with the results of regression 
analyses, there were only small differences between estimates based on model 3 and model $3 a$. Considering all economic factors jointly (model $3 \mathrm{a}$ ), we estimate that $27.3 \%$ of child maltreatment in the Victorian population is attributable to economic disadvantage (or $36.7 \%$ if low-intensity emotional abuse is excluded). When examining specific types of maltreatment (particularly sexual abuse and exposure to domestic violence), the contribution of economic factors was found to be even higher. However, the individual contributions of specific economic factors also varied by type of maltreatment. When considered independently from other economic factors, retrospectively perceived poverty alone accounted for a substantial portion of most attributable fractions but was hardly implicated at all in sexual abuse. For sexual abuse, no significant fraction could be attributed to any specific economic factor but, when considered together, economic factors were significant and strong predictors of sexual abuse.

\subsection{Sensitivity analyses}

Sensitivity to the method of classifying sexual abuse was explored by separating the definition into 'familial sexual abuse' and 'nonfamilial sexual abuse or assault' (our interpretation of each question contributing to the coding of sexual abuse). Findings were similar with respect to each definition, with slightly higher implication of economic factors in nonfamilial abuse or assault (Appendix B). We also explored sensitivity with respect to the coding of neglect, given that parental neglect is perhaps a more continuous variable than other types of maltreatment (i.e., occurring along a spectrum with fewer natural thresholds). In an ordered logistic regression of the 5-point neglect scale, using complete case data and the same independent variables as the multivariate regressions above, poverty was the only significant economic risk factor, with conditional odds ratios of between 2.14 and 2.41. While retrospective perception of poverty was not independently significant in the larger multivariate models of the main analysis, the absolute 
and relative strengths of the associations were not substantially different. Lastly, we also reestimated PAF adding cohort gender as a control variable. Doing this changed estimates only by less than $1 \%$, supporting the assumption that confounding by gender was implausible.

\section{Discussion}

\subsection{Summary of findings and relation to previous studies}

In summary, we found evidence that parent- and family-level economic disadvantage increased young adults' retrospective reports of child maltreatment, even after controlling for a rich set of confounders. These findings support hypotheses of causal effects of economic factors on risk of child maltreatment—particularly effects of poverty and parental unemploymentalthough we cannot be sure they do not reflect omitted variable bias. Poverty remained a strong predictor of most types of maltreatment even after controlling for other economic factors such as parental education, occupation, unemployment, and housing, although this was not the case for sexual abuse. Our findings are consistent with an emerging literature on causal effects of economic factors on child maltreatment and suggest that reducing economic disadvantage may lead to benefits in terms of prevention of most types of maltreatment.

We observed smaller changes in the coefficients for socioeconomic risk factors than were reported by O'Donnell et al. (2010) for the relative socioeconomic disadvantage by area of residence at birth. This is likely to reflect the individual-level of indicators for economic disadvantage recorded in the present study and the use of multiple indicators simultaneously. Our findings with respect to sexual abuse were partly consistent with those reported by Martin et al. (2011) in that the estimated effect of poverty became small and insignificant in multivariate models, however our estimate for maternal education also diminished while parental 
unemployment remained strong. Unfortunately, our data did not allow us to further explore the observation by Berger (2005) of effect modification in single- versus two-parent families.

\subsection{Strengths and limitations}

The main strengths of this study are the inclusion of detailed information about diverse parent and family-level characteristics, most of which were collected from parents early in the child's life, and the representativeness of the sample, supported by a rigorous approach to handling missing data. Although the results of multiple imputation suggest that people who experienced child maltreatment or economic disadvantage were substantially more likely to have missing data (e.g., from loss to follow-up), the associations between these variables changed less with multiple imputation. Supporting this, no statistically significant differences were observed between the complete case and multiply imputed odds ratios.

While the robustness of estimates to observed confounders supports causal effects, it is possible that unobserved confounders remain. One unobserved confounder with likely causal links to both child maltreatment and economic disadvantage is parental experience of child maltreatment. Parental experience of child maltreatment has potential to produce a range of poor outcomes that are passed on as childhood disadvantage in the next generation, contributing to the intergenerational transmission of child maltreatment (Berzenski, Yates, \& Egeland, 2014). There are well-defined causal pathways between parental experience of child maltreatment and maltreatment of their child (Amos, Furber, \& Segal, 2011). Along these causal pathways sits another group of variables that might be more closely related to both socioeconomic disadvantage and child maltreatment - distortions of mental processing of information (cognition and affect). Crittenden (1999) posits these as being the common cause underlying socioeconomic disadvantage and child neglect. Our results are inconsistent with this hypothesis, however, in that 
the indicators of economic disadvantage that are likely to be more closely related to cognitionparental education and occupation- tended to lose statistical significance in multivariate models, while retrospective perception of childhood poverty often remained strong and significant (our findings with respect to sexual abuse, however, may be more consistent with Crittenden's hypothesis). Whereas this finding supports prior research and theory linking poverty and child maltreatment, it must also be viewed with caution for two reasons. First, the poverty measure reflects only retrospective perceptions of poverty. It is possible that adults who were subject to maltreatment—or certain types thereof—as children are more likely to retrospectively perceive living in poverty than others raised in similar economic circumstances. Second, given that the analyses adjust for actual levels of parental education and work, the estimate associated with the poverty coefficient may reflect a variety of things, including parental financial management, as well as social welfare benefit receipt.

The association of economic factors with child maltreatment may also result from community-level factors that were not included in our analysis. For example, neighborhood selection and residence is related to households' individual economic characteristics, and neighborhood disadvantage has also been found to influence child maltreatment (Coulton, Korbin, \& Su, 1999). Access and affordability of services are also related to economic factors. For example, early childhood education programs have been found to be protective against child maltreatment in low-income and at-risk populations but may be less accessible due to cost considerations (Duncan, Ludwig, \& Magnuson, 2007).

This analysis does not yield much insight into the mechanisms through which economic disadvantage may increase child maltreatment. If limited resources were the driving factor, stronger effects might be expected for neglect than other types of maltreatment. Our findings, 
however, indicate a greater role of economic factors in other types of maltreatment, especially physical and sexual abuse and domestic violence. The relationship between poverty and violence is a topic of some debate with respect to directions and mechanisms of causality (see for example Crutchfield \& Wadsworth, 2003). While the present study provides some evidence about the specific aspects of economic disadvantage that contribute to causality, it does not contribute to our understanding of the underlying mechanisms involved. Further research on the factors that mediate or moderate the relationship between economic disadvantage and child maltreatment (and violence in general) will help to identify key points for intervention in the causal pathways.

Like most studies of child maltreatment, there are inherent limitations with our measures of abuse and neglect. Self-reported measures, like other measures, do not detect all child maltreatment (Smith, Ireland, Thornberry, \& Elwyn, 2008). The prevalence of neglect among our complete cases was low compared with other studies (Price-Robertson et al., 2010) but increased substantially with multiple imputation. Retrospective self-reports are also susceptible to recall bias; for example, economically disadvantaged people may be more likely to perceive their childhoods as being neglectful or abusive. This is mostly a concern for the measures of neglect and emotional abuse, for which questions were more subjective. Compared with child protection records, self-report measures detect higher rates and a different ratio of types of maltreatment, which in part reflects differing evidentiary thresholds and sensitivities of detection in child protection systems (Price-Robertson et al., 2010). Self-reported measures collected during childhood may be less susceptible to recall biases but complicate an observational study by imposing ethical responsibilities on researchers to intervene (e.g., report to protective services) whenever maltreatment is suspected. Report by parents is sometimes used, and approximation of maltreatment from nonspecific parental behaviors has also been associated 
with economic disadvantage, child protection involvement, and child outcomes (Berger, 2004, 2007; Font \& Berger, 2015).

Finally, while we were able to control for experience of parental separation, we were unable to make the finer-grained distinction between family structures with and without stepparents in the household.

\subsection{Generalization to other contexts}

The current findings have clear relevance to the Australian context. Most other research on the economic determinants of child maltreatment uses data from the U.S. (Berger \& Waldfogel, 2011). Rates of investigation and substantiation of child maltreatment in the U.S. are slightly higher than in Australia (Gilbert et al., 2009), although this may reflect system factors (legislative and practice frameworks, such as thresholds for intervention) more than the underlying incidence of maltreatment. Self-reported data are broadly similar, but variation in survey design and sampling are likely to be an even greater source of variation in estimates and there have been only a few population-based studies of self-reported experience of child maltreatment in Australia (Price-Robertson et al., 2010). As with Native Americans and blacks, Australian Aboriginal populations experience higher levels of most disadvantage, and also experience greater levels of involvement with child protection services (Delfabbro et al., 2010b; Wildeman et al., 2014). However, Aboriginal people compose only a very small proportion of the Victorian population (too few to be analyzed in this sample), so the findings presented in this study cannot be generalized to Indigenous Australians. The Australian context does differ from the U.S. in having lower levels of poverty and disadvantage - both relative and absolute (OECD, 2008). This would mean that economic factors are likely to have a greater proportional role in 
child maltreatment in the U.S. compared with the attributable fractions presented here, even if the effects of economic disadvantage on child maltreatment are the same.

Whether the effects are the same is difficult to determine from the limited range of comparable research. Of studies investigating the causal effects of economic disadvantage on child maltreatment, only Berger (2005) explores a comparable range of economic factors simultaneously and he was able to examine outcomes only in terms of parent-reported physical abuse. One might expect the underlying effects of economic disadvantage on child maltreatment to be modified by certain protective factors at the societal level—namely, access to welfare services and financial safety nets that limit or reduce other impacts of economic disadvantage. In this respect, Australia falls at the more supportive end of the spectrum, implying that effects of economic disadvantage on child maltreatment may be stronger in many other countries than the effects estimated here. However, associations between economic disadvantage and child maltreatment are observed even in countries that could be considered world leaders in family support, such as Finland and Denmark (Hearn et al., 2004, and Hestbæk, 1999, in Berger \& Waldfogel, 2011).

\subsection{Conclusions and implications for policy}

Our finding that a smaller fraction of neglect could be attributed to economic factors than for other types of maltreatment indicates that, at least in welfare states like Australia, the link between economic disadvantage and child maltreatment is unlikely to be as simple as merely reflecting insufficient access to economic resources. This is supported by our findings with respect to the importance of other economic factors, after controlling for poverty. Merely addressing the financial aspects of economic disadvantage (increasing welfare payments, etc.) is unlikely to be sufficient to address the economic determinants of child maltreatment. Economic 
disadvantage is multifaceted, affecting risk of child maltreatment through multiple factors. Addressing the economic determinants of child maltreatment will likewise require a multifaceted approach to intervention and policy change.

Given that parents have prime responsibility for providing a safe and caring environment for children, the focus of prevention efforts in child abuse and neglect has historically been directed to addressing parental skills deficits; through public awareness raising, targeted information, direct education (parenting programs), and modeling of effective parenting practices. Little attention has been paid to the role that economic disadvantage might play in parents' capacity to access these messages and supports and translate them into improvements in parenting. As Mullan and Higgins (2014) demonstrated using data from a representative sample of Australian children, family environments and, in particular, harsh parenting practices, vary throughout the population and are not found solely in those who were socially or economically disadvantaged. It may be that disadvantage makes it less likely that parents will be exposed to, or respond appropriately to interventions that reduce the risk of abusive or neglectful parenting. This suggests that there is value in both targeting specific problematic behaviors and at the same time addressing the structural and personal factors that are associated with greater risk of maltreatment.

Reducing economic disadvantage to an extent that is consistent with our analysis is unlikely; it is unreasonable to expect all parents to be tertiary educated or have professional/managerial occupations. There is however room to improve access to education and differentiation of occupational classes, and it is reasonable to expect that the risk of maltreatment among lower-educated parents in manual occupations may be brought into closer alignment with their less disadvantaged counterparts. If we are to develop effective interventions in this space, 
we will need to better understand the mechanisms through which these factors affect child maltreatment.

Unemployment was perhaps the most modifiable economic risk factor for child maltreatment, despite generous welfare provisions in Australia. Thus, reducing unemployment itself may be an effective intervention against child maltreatment. Lastly, while this analysis indicates that reducing economic disadvantage has substantial potential to reduce child maltreatment, it does not provide any insight as to how reductions in economic disadvantage should be achieved or how reductions in excess risk might be otherwise achieved in economically disadvantaged populations. It is clear though that effective prevention policy must include a range of strategies and multiple levels of intervention (both universal and targeted) and that economic factors play a key role in the prevalence of most forms of child maltreatment. 


\section{Acknowledgements}

The ATP study is located at the Royal Children's Hospital in Melbourne and is a collaboration between Deakin University, the University of Melbourne, the Australian Institute of Family Studies, the University of New South Wales, the University of Otago (NZ), and the Royal Children's Hospital; further information available at www.aifs.gov.au/atp. Funding for this analysis was supported by a PhD scholarship from the University of South Australia, and the South Australian Health Economics Collaborative (funded by the South Australian Department of Health). The views expressed in this paper are those of the authors and may not reflect those of their organizational affiliations, nor of other collaborating individuals or organizations. We acknowledge all collaborators who have contributed to the Australian Temperament Project, especially Leah Bromfield, who was involved with the original design of survey questions concerning child maltreatment, and Professors Ann Sanson, Margot Prior, and Frank Oberklaid, and Ms. Diana Smart. We would also like to sincerely thank the participating families for their time and invaluable contribution to the study.

The authors declare that they have no conflict of interest. All procedures performed in studies involving human participants were in accordance with the ethical standards of the institutional and/or national research committee and with the 1964 Declaration of Helsinki and its later amendments or comparable ethical standards. Informed consent was obtained from all individual participants included in the study. 


\section{References}

Amos, J., Furber, G., \& Segal, L. (2011). Understanding maltreating mothers: A synthesis of relational trauma, attachment disorganization, structural dissociation of the personality, and experiential avoidance. Journal of Trauma \& Dissociation, 12(5), 495-509. http://dx.doi.org/10.1080/15299732.2011.593259

Australian Institute of Health and Welfare. (2015). Child protection australia: 2013-14. (Child Welfare Series No. 61). Canberra: AIHW. Retrieved from http://www.aihw.gov.au/publication-detail/?id=60129550762

Berger, L. M. (2004). Income, family structure, and child maltreatment risk. Children and Youth Services Review, 26(8), 725-748. http://dx.doi.org/10.1016/j.childyouth.2004.02.017

Berger, L. M. (2005). Income, family characteristics, and physical violence toward children. Child Abuse and Neglect, 29(2), 107-133. http://dx.doi.org/10.1016/j.chiabu.2004.02.006

Berger, L. M. (2007). Socioeconomic factors and substandard parenting. Social Service Review, 81(3), 485-522. http://dx.doi.org/10.1086/520963

Berger, L. M., \& Brooks-Gunn, J. (2005). Socioeconomic status, parenting knowledge and behaviors, and perceived maltreatment of young low-birth-weight children. Social Service Review, 79(2), 237-267. http://dx.doi.org/10.1086/428957

Berger, L. M., Collins, J. M., Font, S. A., Gjertson, L., Slack, K. S., \& Smeeding, T. (2015). Home foreclosure and child protective services involvement. Pediatrics, 136(2), 299-307. http://dx.doi.org/10.1542/peds.2014-2832

Berger, L. M., \& Waldfogel, J. (2011). Economic determinants and consequences of child maltreatment. OECD Social, Employment and Migration Working Papers, (OECD Social, Employment and Migration Working Papers No. 111). OECD Publishing. Retrieved from http://dx.doi.org/10.1787/5kgf09zj7h9t-en 
Berzenski, S., Yates, T., \& Egeland, B. (2014). A multidimensional view of continuity in intergenerational transmission of child maltreatment. In J. E. Korbin \& R. D. Krugman (Eds.), Handbook of child maltreatment (Vol. 2, pp. 115-129). Dordrecht: Springer Netherlands.

Broom, L., Lancaster, F., \& Zubrzycki, J. (1976). Opportunity and attainment in australia. Canberra: Australian National University Press.

Brotherton, P. L., Kotler, T., \& Hammond, S. B. (1979). Development of an australian index of social class. Australian Psychologist, 14(1), 77-83. http://dx.doi.org/10.1080/00050067908254344

Brown, J., Cohen, P., Johnson, J. G., \& Salzinger, S. (1998). A longitudinal analysis of risk factors for child maltreatment: Findings of a 17-year prospective study of officially recorded and self-reported child abuse and neglect. Child Abuse and Neglect, 22(11), 1065-1078. http://dx.doi.org/10.1016/S0145-2134(98)00087-8

Cancian, M., Yang, M.-Y., \& Slack, K. S. (2013). The effect of additional child support income on the risk of child maltreatment. Social Service Review, 87(3), 417-437. http://dx.doi.org/doi:10.1086/671929

Conger, R. D., \& Donnellan, M. B. (2007). An interactionist perspective on the socioeconomic context of human development. Annual Review of Psychology, 58, 175-199. http://dx.doi.org/10.1146/annurev.psych.58.110405.085551

Coulton, C. J., Korbin, J. E., \& Su, M. (1999). Neighborhoods and child maltreatment: A multilevel study. Child Abuse and Neglect, 23(11), 1019-1040. 
Crittenden, P. M. (1999). Child neglect: Causes and contributors. In H. Dubowitz (Ed.), Neglected children: Research, practice, and policy (pp. 47-69). Thousand Oaks, CA: SAGE Publications, Inc.

Crutchfield, R., \& Wadsworth, T. (2003). Poverty and violence. In W. Heitmeyer \& J. Hagan (Eds.), International handbook of violence research (pp. 67-82): Springer Netherlands.

Delfabbro, P., Hirte, C., Rogers, N., \& Wilson, R. (2010a). Longitudinal trends in child protection statistics in south australia: A study of unit record data. Children Australia, 35(3), 4-10.

Delfabbro, P., Hirte, C., Rogers, N., \& Wilson, R. (2010b). The over-representation of young aboriginal or torres strait islander people in the south australian child system: A longitudinal analysis. Children and Youth Services Review, 32(10), 1418-1425. http://dx.doi.org/10.1016/j.childyouth.2010.06.011

Doidge, J. C. (2016). Responsiveness-informed multiple imputation and inverse probabilityweighting in cohort studies with missing data that are non-monotone or not missing at random. Statistical Methods in Medical Research, Advanced online publication. http://dx.doi.org/10.1177/0962280216628902

Doidge, J. C., Edwards, B., Higgins, D. J., \& Segal, L. (2015). Selection bias and missing data in retrospective self-reports of adverse childhood experiences. Manuscript submitted for publication.

Drake, B., \& Jonson-Reid, M. (2014). Poverty and child maltreatment. In J. E. Korbin \& R. D. Krugman (Eds.), Handbook of child maltreatment (Vol. 2, pp. 131-148). Dordrecht: Springer Netherlands. 
Duncan, G. J., Ludwig, J., \& Magnuson, K. A. (2007). Reducing poverty through preschool interventions. Future of Children, 17(2), 143-160. http://dx.doi.org/10.1353/foc.2007.0015

Font, S. A., \& Berger, L. M. (2015). Child maltreatment and children's developmental trajectories in early to middle childhood. Child Development, 86(2), 536-556. http://dx.doi.org/10.1111/cdev.12322

Gilbert, R., Widom, C. S., Browne, K., Fergusson, D., Webb, E., \& Janson, S. (2009). Burden and consequences of child maltreatment in high-income countries. The Lancet, 373(9657), 68-81.

Glass, T. A., Goodman, S. N., Hernán, M. A., \& Samet, J. M. (2013). Causal inference in public health. Annual Review of Public Health, 34, 61-75. http://dx.doi.org/10.1146/annurevpublhealth-031811-124606

Goldsworthy, K. (2015). What is child abuse and neglect? CFCA Resource Sheet, Melbourne: Australian Institute of Family Studies. Retrieved from https://aifs.gov.au/cfca/publications/what-child-abuse-and-neglect

Greenland, S., \& Drescher, K. (1993). Maximum likelihood estimation of the attributable fraction from logistic models. Biometrics, 49(3), 865-872. http://dx.doi.org/10.2307/2532206

Hearn, J., Pösö, T., Smith, C., White, S., \& Korpinen, J. (2004). What is child protection? Historical and methodological issues in comparative research on lastensuojelu/child protection. International Journal of Social Welfare, 13(1), 28-41. http://dx.doi.org/10.1111/j.1369-6866.2004.00295.x 
Hestbæk, A. D. (1999). Social background and placement course - the case of denmark. International Journal of Social Welfare, 8(4), 267-276. http://dx.doi.org/10.1111/1468$\underline{2397.00093}$

Hussey, J. M., Chang, J. J., \& Kotch, J. B. (2006). Child maltreatment in the united states: Prevalence, risk factors, and adolescent health consequences. Pediatrics, 118(3), 933942. http://dx.doi.org/10.1542/peds.2005-2452

James, M. (1994). Domestic violence as a form of child abuse: Identification and prevention. (NCPC Issues No. 2). Melbourne: National Child Protection Clearinghouse (Australia). Retrieved from https://www3.aifs.gov.au/cfca/publications/domestic-violence-formchild-abuse-identification

Kitzmann, K. M., Gaylord, N. K., Holt, A. R., \& Kenny, E. D. (2003). Child witnesses to domestic violence: A meta-analytic review. Journal of Consulting and Clinical Psychology, 71(2), 339-352.

Lamont, A., \& Price-Robertson, R. (2013). Risk and protective factors for child abuse and neglect. CFCA Resource Sheet, Melbourne: Australian Institute of Family Studies. Retrieved from https://www3.aifs.gov.au/cfca/publications/risk-and-protective-factorschild-abuse-and-neglect

Lee, B. J., \& Goerge, R. M. (1999). Poverty, early childbearing, and child maltreatment: A multinomial analysis. Children and Youth Services Review, 21(9-10), 755-780. http://dx.doi.org/10.1016/S0190-7409(99)00053-5

Martin, A., Najman, J. M., Williams, G. M., Bor, W., Gorton, E., \& Alati, R. (2011). Longitudinal analysis of maternal risk factors for childhood sexual abuse: Early attitudes 
and behaviours, socioeconomic status, and mental health. Australian and New Zealand Journal of Psychiatry, 45(8), 629-637. http://dx.doi.org/10.3109/00048674.2011.587395

Mullan, K., \& Higgins, D. J. (2014). A safe and supportive family environment for children: Key components and links to child outcomes. DSS Occasional Paper No. 52, Canberra: Department of Social Services (Australia). Retrieved from http://www.dss.gov.au/aboutthe-department/publications-articles/research-publications/occasional-paper-series

Munro, E., Taylor, J. S., \& Bradbury-Jones, C. (2013). Understanding the causal pathways to child maltreatment: Implications for health and social care policy and practice. Child Abuse Review, 23(1), 61-74. http://dx.doi.org/10.1002/car.2266

Newson, R. B. (2013). Attributable and unattributable risks and fractions and other scenario comparisons. Stata Journal, 13(4), 672-698.

O’Donnell, M., Nassar, N., Leonard, H., Jacoby, P., Mathews, R., Patterson, Y., \& Stanley, F. (2010). Characteristics of non-aboriginal and aboriginal children and families with substantiated child maltreatment: A population-based study. International Journal of Epidemiology, 39(3), 921-928. http://dx.doi.org/10.1093/ije/dyq005

OECD. (2008). Growing unequal? Income distribution and poverty in oecd countries. Paris: OECD Publishing.

Pelton, L. H. (1978). Child abuse and neglect: The myth of classlessness. The American Journal of Orthopsychiatry, 48, 608-617.

Price-Robertson, R., Bromfield, L., \& Vassallo, S. (2010). The prevalence of child abuse and neglect. National Child Protection Clearinghouse Resource Sheet, Melbourne: Australian Institute of Family Studies, Australian Government. Retrieved from http://www.aifs.gov.au/nch/pubs/sheets/rs6/rs6.html 
Prior, M., Sanson, A., Smart, D., \& Oberklaid, F. (2000). Pathways from infancy to adolescence: Australian temperament project 1983-2000. Melbourne, Australia: Australian Institute of Family Studies.

Sanson, A., \& Oberklaid, F. (1985). Normative data on temperament in australian infants. Australian Journal of Psychology, 37(2), 185-195.

Scott, D. (2014). Australian legal definitions: When is a child in need of protection? CFCA Resource Sheet, Melbourne: Australian Institute of Family Studies. Retrieved from https://aifs.gov.au/cfca/publications/australian-legal-definitions-when-child-need-pro

Smith, C. A., Ireland, T. O., Thornberry, T. P., \& Elwyn, L. (2008). Childhood maltreatment and antisocial behavior: Comparison of self-reported and substantiated maltreatment. American Journal of Orthopsychiatry, 78(2), 173-186. http://dx.doi.org/10.1037/0002$\underline{9432.78 .2 .173}$

Stith, S. M., Liu, T., Davies, L. C., Boykin, E. L., Alder, M. C., Harris, J. M., . . Dees, J. E. M. E. G. (2009). Risk factors in child maltreatment: A meta-analytic review of the literature. Aggression and Violent Behavior, 14(1), 13-29. http://dx.doi.org/10.1016/j.avb.2006.03.006

U.S. Department of Health and Human Services. (2015). 2015 prevention resource guide: Making meaningful connections. Washington, D.C.: Department of Health and Human Services (USA). Retrieved from https://www.childwelfare.gov/pubpdfs/guide.pdf

van Buuren, S. (2007). Multiple imputation of discrete and continuous data by fully conditional specification. Statistical Methods in Medical Research, 16. http://dx.doi.org/10.1177/0962280206074463 
Vassallo, S., \& Sanson, A. (Eds.). (2013). The australian temperament project: The first 30 years. Melbourne: The Australian Institute of Family Studies.

White, I. R., Daniel, R., \& Royston, P. (2010). Avoiding bias due to perfect prediction in multiple imputation of incomplete categorical variables. Computational Statistics \& Data Analysis, 54(10), 2267-2275. http://dx.doi.org/10.1016/j.csda.2010.04.005

Wildeman, C., Emanuel, N., Leventhal, J. M., Putnam-Hornstein, E., Waldfogel, J., \& Lee, H. (2014). The prevalence of confirmed maltreatment among u.S. Children, 2004 to 2011. JAMA Pediatrics, 168(8), 706-713. http://dx.doi.org/10.1001/jamapediatrics.2014.410

Woodward, L. J., \& Fergusson, D. M. (2002). Parent, child, and contextual predictors of childhood physical punishment. Infant and Child Development, 11(3), 213-235. http://dx.doi.org/10.1002/icd.252

Zellman, G. L. (1992). The impact of case characteristics on child abuse reporting decisions. Child Abuse and Neglect, 16(1), 57-74. 
Table 1

Description of main variables.

\begin{tabular}{|c|c|c|}
\hline Item & Response coding & Recorded at \\
\hline \multicolumn{3}{|l|}{ Economic factors } \\
\hline $\begin{array}{l}\text { Mother's and father's } \\
\text { education (highest achieved) }\end{array}$ & $\begin{array}{l}\text { Low }=\text { less than tertiary education (based on 8- } \\
\text { point scale adapted from Brotherton, Kotler, \& } \\
\text { Hammond, 1979) }\end{array}$ & $\begin{array}{l}4-8 \text { months or } \\
\text { earliest record }\end{array}$ \\
\hline $\begin{array}{l}\text { Mother's and father's } \\
\text { occupation }\end{array}$ & $\begin{array}{l}\text { Low }=\text { neither professional nor managerial (text, } \\
\text { coded according to 6-point scale by Broom, } \\
\text { Lancaster, \& Zubrzycki, 1976s) }\end{array}$ & $\begin{array}{l}4-8 \text { months or } \\
\text { earliest record }\end{array}$ \\
\hline Parental unemployment & $\begin{array}{l}\text { Frequent }=\text { at least } 2 \text { from a possible } 10 \\
\text { affirmative responses to "Has father/mother been } \\
\text { unemployed, but wishing to work, over the last } 12 \\
\text { months?" }\end{array}$ & $\begin{array}{l}9-10,11-12,12-13, \\
13-14, \text { and } 15-16 \\
\text { years }\end{array}$ \\
\hline Housing & $\begin{array}{l}\text { Other than owner-occupied home or flat (from six } \\
\text { possible check boxes) }\end{array}$ & $\begin{array}{l}3-4,5-6 \text {, and } 7-8 \\
\text { years (highest) }\end{array}$ \\
\hline Poverty & $\begin{array}{l}\text { At least "somewhat true" on 5-point scale to } \\
\text { "Your family was poor and struggled to make } \\
\text { ends meet"" }\end{array}$ & $23-24$ years \\
\hline \multicolumn{3}{|l|}{ Child maltreatment } \\
\hline Emotional abuse & $\begin{array}{l}\text { "very true" (high intensity) or "somewhat true" } \\
\text { (low intensity) on a 5-point scale to "You } \\
\text { experienced verbal treatment from your parent/s } \\
\text { that made you feel embarrassed, humiliated or } \\
\text { scared (e.g. shouting, name calling, threats)" }\end{array}$ & 23-24 years \\
\hline Neglect & $\begin{array}{l}\text { At least "somewhat untrue" to "The care taken of } \\
\text { you by your parent/s was the right amount (e.g. } \\
\text { they watched out for you, fed you properly, gave } \\
\text { you attention)" }\end{array}$ & $23-24$ years \\
\hline Physical abuse & $\begin{array}{l}\text { "Yes" to "Your parent/s used harsh physical } \\
\text { treatment (e.g. smacking hitting) to discipline } \\
\text { you" AND "Did you ever suffer effects that lasted } \\
\text { to the next day or longer (e.g. bruising, marking, } \\
\text { pain, soreness)?" }\end{array}$ & 23-24 years \\
\hline Sexual abuse & $\begin{array}{l}\text { "Yes" to "A family member did, or tried to do } \\
\text { sexual things to you" OR "You had a } \\
\text { [nonconsensual] sexual experience with a person } \\
\text { who was not a family member before you were } \\
16 "\end{array}$ & 23-24 years \\
\hline Witnessing domestic violence & $\begin{array}{l}\text { "somewhat true" or "very true" on a 5-point scale } \\
\text { to "There was physical violence between the } \\
\text { adults caring for you" }\end{array}$ & 23-24 years \\
\hline
\end{tabular}


Table 2

Participant characteristics, before and after multiple imputation.

\begin{tabular}{|c|c|c|c|c|}
\hline \multirow{2}{*}{$\frac{\text { Characteristic }}{N}$} & \multicolumn{2}{|c|}{$\begin{array}{l}\text { Whole cohort, } \\
\% \text { (\% missing) }\end{array}$} & \multirow{2}{*}{$\begin{array}{c}\text { Complete cases, } \\
\% \\
547\end{array}$} & \multirow{2}{*}{$\begin{array}{c}\text { Multiply } \\
\text { imputed, \% } \\
2,443\end{array}$} \\
\hline & 2,443 & & & \\
\hline Female & 48.1 & $(0.0)$ & 59.6 & 48.1 \\
\hline \multicolumn{5}{|l|}{ Child maltreatment } \\
\hline Any child abuse or neglect & 24.3 & $(61.1)$ & 22.3 & 37.2 \\
\hline High-intensity emotional abuse & 3.3 & $(60.6)$ & 3.3 & 6.2 \\
\hline Low-intensity emotional abuse & 13.7 & $(60.6)$ & 12.4 & 18.9 \\
\hline Neglect & 2.8 & $(60.5)$ & 3.1 & 7.9 \\
\hline Physical abuse & 5.8 & $(60.5)$ & 5.7 & 9.6 \\
\hline Sexual abuse & 5.8 & $(60.7)$ & 4.4 & 11.0 \\
\hline Witnessed domestic violence & 4.4 & $(60.6)$ & 4.2 & 8.9 \\
\hline \multicolumn{5}{|l|}{ Child health } \\
\hline \multicolumn{5}{|l|}{ At least 2 investigated health problems by $3-4$} \\
\hline $\mathrm{y}$ & 7.4 & $(32.8)$ & 6.0 & 7.5 \\
\hline Birthweight $<3 \mathrm{rd} \mathrm{pc}$ & 3.2 & $(11.3)$ & 2.7 & 3.6 \\
\hline $\begin{array}{l}\text { Retrospective self-report of cognitive or } \\
\text { behavioral problems }\end{array}$ & 10.9 & $(60.7)$ & 11.5 & 14.8 \\
\hline $\begin{array}{l}\text { Retrospective self-report of physical health } \\
\text { problems }\end{array}$ & 12.0 & $(60.7)$ & 12.1 & 14.6 \\
\hline \multicolumn{5}{|l|}{ Demographic factors } \\
\hline Large family (>4 children) & 5.8 & $(32.4)$ & 5.1 & 6.8 \\
\hline $\begin{array}{l}\text { Parental immigration from non-English- } \\
\text { speaking country }\end{array}$ & 22.0 & $(2.3)$ & 14.4 & 22.2 \\
\hline Parental separation & 20.2 & $(49.5)$ & 18.3 & 23.9 \\
\hline Young father $(<22 \mathrm{y})$ & 2.5 & $(1.6)$ & 0.5 & 2.8 \\
\hline Young mother $(<22 \mathrm{y})$ & 7.3 & $(0.1)$ & 1.6 & 7.4 \\
\hline \multicolumn{5}{|l|}{ Economic factors } \\
\hline Lack of homeownership & 8.7 & $(22.7)$ & 5.3 & 9.3 \\
\hline Maternal education, less than tertiary & 76.1 & $(0.9)$ & 68.4 & 76.3 \\
\hline $\begin{array}{l}\text { Maternal occupation, not } \\
\text { professional/managerial }\end{array}$ & 73.9 & (1.9) & 66.5 & 74.2 \\
\hline Paternal education, less than tertiary & 70.8 & (2.7) & 62.2 & 71.1 \\
\hline \multicolumn{5}{|l|}{ Paternal occupation, not } \\
\hline Recurrent/protracted parental unemployment & 27.0 & $(51.7)$ & 23.2 & 38.1 \\
\hline Retrospective perception of poverty & 17.8 & $(60.5)$ & 14.3 & 24.2 \\
\hline \multicolumn{5}{|l|}{ Parental mental health and substance use } \\
\hline Father ex or heavy drinker & 7.9 & $(41.5)$ & 6.4 & 9.5 \\
\hline Mother ex or heavy drinker & 2.1 & $(41.5)$ & 1.3 & 3.3 \\
\hline Parental mental illness & 6.6 & $(61.1)$ & 5.7 & 11.2 \\
\hline Parental smoking (current or past) & 67.4 & $(40.8)$ & 63.4 & 70.2 \\
\hline Parental substance use problems & 4.9 & $(61.1)$ & 4.6 & 8.1 \\
\hline
\end{tabular}

See section 2.2 and Table 1 for description of variables. 
Table 3

Risk of child maltreatment by number of economic risk factors.

Estimated prevalence of maltreatment by number of economic risk factors, $\%$ (prevalence of number of economic risk factors, \%)

\begin{tabular}{|c|c|c|c|c|c|c|c|c|}
\hline \multirow[b]{2}{*}{ Type of child maltreatment } & & & & & & & & \\
\hline & 0 & 1 & 2 & 3 & 4 & 5 & 6 & 7 \\
\hline (prevalence of economic risk score, \%) & $(8.0)$ & $(7.1)$ & $(11.8)$ & $(14.9)$ & $(26.9)$ & $(19.2)$ & $(9.8)$ & $(2.4)$ \\
\hline High-intensity emotional abuse & 2.1 & 4.1 & 4.4 & 5.7 & 5.1 & 7.7 & 11.7 & 16.8 \\
\hline Low-intensity emotional abuse & 8.5 & 15.3 & 17.4 & 15.6 & 16.5 & 21.8 & 31.4 & 44.6 \\
\hline Neglect & 4.4 & 6.6 & 6.1 & 8.1 & 6.2 & 8.7 & 14.1 & 17.2 \\
\hline Physical abuse & 4.6 & 6.6 & 7.1 & 7.3 & 6.7 & 12.6 & 19.4 & 30.1 \\
\hline Sexual abuse & 1.9 & 5.0 & 7.8 & 6.3 & 10.0 & 15.1 & 23.1 & 31.6 \\
\hline Witnessing of domestic violence & 1.4 & 2.5 & 4.5 & 5.7 & 7.4 & 13.1 & 20.5 & 31.1 \\
\hline Any & 16.9 & 27.7 & 31.8 & 33.3 & 33.2 & 44.6 & 59.9 & 77.7 \\
\hline
\end{tabular}

Data are multiply imputed $(n=2443)$ estimates of the probability of experiencing each type of maltreatment given the number of economic risk factors also experienced. Economic risk factors include lack of homeownership; maternal/paternal education, less than tertiary; maternal/paternal occupation, not professional/managerial; recurrent or protracted parental unemployment; and retrospective perception of poverty. 
Table 4

Regression models: Economic determinants of child maltreatment.

\begin{tabular}{|c|c|c|c|c|c|c|c|c|}
\hline \multirow[b]{3}{*}{ Economic factor, by child maltreatment outcome } & \multicolumn{8}{|c|}{ Estimated odds ratio for child maltreatment } \\
\hline & \multicolumn{2}{|c|}{ Unadjusted models } & \multicolumn{6}{|c|}{ Multivariate models } \\
\hline & $\begin{array}{c}\text { Complete } \\
\text { case }\end{array}$ & $\begin{array}{l}\text { Multiply } \\
\text { imputed }\end{array}$ & 1 & $1 \mathrm{a}$ & 2 & $2 \mathrm{a}$ & 3 & $3 \mathrm{a}$ \\
\hline Any child maltreatment, joint significance & & & $* * *$ & $* * *$ & $* * *$ & ** & $* * *$ & $* *$ \\
\hline Lack of homeownership & $2.24 * *$ & $2.52 * * *$ & $2.02 * * *$ & $1.76^{* *}$ & $1.77 * *$ & $1.57 *$ & $1.70 *$ & 1.50 \\
\hline Maternal education, less than tertiary & 1.40 & $1.64 * * *$ & $1.39 *$ & $1.42 * *$ & $1.36^{*}$ & $1.39 *$ & 1.31 & 1.31 \\
\hline Maternal occupation, not professional/managerial & $1.63 * *$ & $1.43 * *$ & 0.90 & 0.88 & 0.84 & 0.83 & 0.87 & 0.87 \\
\hline Paternal education, less than tertiary & 1.39 & $1.46^{* * *}$ & 1.00 & 0.97 & 0.98 & 0.96 & 0.98 & 0.95 \\
\hline Paternal occupation, not professional/managerial & $1.74 * * *$ & $1.57 * * *$ & 1.27 & 1.22 & 1.20 & 1.15 & 1.18 & 1.14 \\
\hline Recurrent/protracted parental unemployment & $2.57 * * *$ & $2.33 * * *$ & $2.08 * * *$ & $1.78 * * *$ & $1.82 * * *$ & $1.60 * * *$ & $1.71 * * *$ & $1.56 * * *$ \\
\hline Retrospective perception of poverty & $2.93 * * *$ & $2.94 * * *$ & & $2.30 * * *$ & & $2.09 * * *$ & & $1.90 * * *$ \\
\hline High-intensity emotional abuse, joint significance & & & $*$ & & & & & \\
\hline Lack of homeownership & $3.87 * *$ & 1.87 & 1.51 & 1.30 & 1.34 & 1.19 & 1.27 & 1.12 \\
\hline Maternal education, less than tertiary & $3.82 *$ & 1.61 & 1.32 & 1.34 & 1.30 & 1.32 & 1.24 & 1.24 \\
\hline Maternal occupation, not professional/managerial & $4.16^{*}$ & 1.53 & 1.11 & 1.08 & 1.04 & 1.02 & 1.07 & 1.06 \\
\hline Paternal education, less than tertiary & 2.18 & 1.23 & 0.87 & 0.85 & 0.84 & 0.83 & 0.84 & 0.82 \\
\hline Paternal occupation, not professional/managerial & 2.40 & 1.38 & 1.15 & 1.09 & 1.08 & 1.03 & 1.06 & 1.02 \\
\hline Recurrent/protracted parental unemployment & $3.48 * *$ & $2.22 * * *$ & $2.04 * *$ & $1.71 *$ & $1.76^{*}$ & 1.54 & $1.65^{*}$ & 1.48 \\
\hline Retrospective perception of poverty & 2.40 & $2.64 * * *$ & & $2.14 * *$ & & $1.91 *$ & & 1.75 \\
\hline Low-intensity emotional abuse, joint significance & & & $* * *$ & $*$ & & & & \\
\hline Lack of homeownership & 1.14 & $2.00 * *$ & $1.68 *$ & 1.47 & 1.42 & 1.26 & 1.36 & 1.20 \\
\hline Maternal education, less than tertiary & 1.04 & $1.60 * * *$ & $1.64 * *$ & $1.68 * *$ & $1.54 *$ & $1.57 *$ & 1.49 & 1.48 \\
\hline Maternal occupation, not professional/managerial & 1.06 & 1.25 & 0.80 & 0.78 & 0.76 & 0.74 & 0.78 & 0.78 \\
\hline Paternal education, less than tertiary & 0.85 & 1.24 & 0.93 & 0.90 & 0.90 & 0.88 & 0.90 & 0.87 \\
\hline Paternal occupation, not professional/managerial & 1.24 & 1.29 & 1.10 & 1.05 & 1.02 & 0.98 & 1.00 & 0.96 \\
\hline Recurrent/protracted parental unemployment & $2.15 * * *$ & $1.95 * * *$ & $1.81 * * *$ & $1.55^{* *}$ & $1.61 * *$ & 1.41 & $1.53 * *$ & 1.38 \\
\hline Retrospective perception of poverty & $3.02 * * *$ & $2.46 * * *$ & & $2.06 * * *$ & & $1.92 * * *$ & & $1.77 * * *$ \\
\hline
\end{tabular}

(table continues) 


\begin{tabular}{|c|c|c|c|c|c|c|c|c|}
\hline & \multicolumn{8}{|c|}{ Estimated odds ratio for child maltreatment } \\
\hline & \multicolumn{2}{|c|}{ Unadjusted models } & \multicolumn{6}{|c|}{ Multivariate models } \\
\hline & $\begin{array}{c}\text { Complete } \\
\text { case }\end{array}$ & $\begin{array}{l}\text { Multiply } \\
\text { imputed }\end{array}$ & 1 & $1 \mathrm{a}$ & 2 & $2 \mathrm{a}$ & 3 & $3 a$ \\
\hline \multicolumn{9}{|l|}{ Neglect, joint significance } \\
\hline Lack of homeownership & 2.48 & 1.37 & 1.18 & 1.00 & 1.05 & 0.92 & 0.98 & 0.83 \\
\hline Maternal education, less than tertiary & 2.20 & 1.47 & 1.52 & 1.54 & 1.49 & 1.52 & 1.43 & 1.38 \\
\hline Maternal occupation, not professional/managerial & 2.40 & 1.22 & 0.90 & 0.88 & 0.88 & 0.87 & 0.91 & 0.93 \\
\hline Paternal education, less than tertiary & 1.48 & 1.10 & 0.91 & 0.88 & 0.88 & 0.86 & 0.89 & 0.87 \\
\hline Paternal occupation, not professional/managerial & 1.29 & 1.12 & 0.97 & 0.92 & 0.95 & 0.91 & 0.92 & 0.89 \\
\hline Recurrent/protracted parental unemployment & $2.39 *$ & $1.83^{*}$ & $1.79 *$ & 1.50 & 1.52 & 1.33 & 1.42 & 1.26 \\
\hline Retrospective perception of poverty & $2.61 *$ & $2.43 * *$ & & $2.19 *$ & & 1.91 & & 1.74 \\
\hline Physical abuse, joint significance & & & $* * *$ & $* *$ & $* * *$ & $* *$ & $* * *$ & $* *$ \\
\hline Lack of homeownership & $2.91 *$ & $2.10^{*}$ & 1.82 & 1.46 & 1.93 & 1.59 & 1.84 & 1.50 \\
\hline Maternal education, less than tertiary & 1.14 & 0.92 & 0.67 & 0.68 & 0.71 & 0.72 & 0.68 & 0.69 \\
\hline Maternal occupation, not professional/managerial & 1.24 & 0.97 & 0.71 & 0.66 & 0.67 & 0.64 & 0.69 & 0.65 \\
\hline Paternal education, less than tertiary & 1.52 & $1.52 *$ & 0.99 & 0.94 & 0.99 & 0.95 & 0.99 & 0.95 \\
\hline Paternal occupation, not professional/managerial & $3.27 * * *$ & $2.50 * * *$ & $2.83 * * *$ & $2.68 * * *$ & $2.97 * * *$ & $2.83 * * *$ & $2.97 * * *$ & $2.85 * * *$ \\
\hline Recurrent/protracted parental unemployment & $2.20 * *$ & $2.11 * * *$ & $1.86^{* *}$ & 1.40 & 1.66 & 1.29 & 1.60 & 1.30 \\
\hline Retrospective perception of poverty & $4.31 * * *$ & $4.05 * * *$ & & $3.41 * * *$ & & $3.27 * * *$ & & $3.11 * * *$ \\
\hline Sexual abuse, joint significance & & & $* * *$ & $* * *$ & $* * *$ & $* *$ & $* * *$ & $* *$ \\
\hline Lack of homeownership & 1.67 & $2.79 * * *$ & $2.07 *$ & 1.92 & 1.87 & 1.78 & 1.80 & 1.73 \\
\hline Maternal education, less than tertiary & 1.80 & $2.12 * * *$ & 1.23 & 1.24 & 1.24 & 1.25 & 1.17 & 1.15 \\
\hline Maternal occupation, not professional/managerial & $2.60 *$ & $2.08 * *$ & 1.25 & 1.23 & 1.17 & 1.16 & 1.21 & 1.23 \\
\hline Paternal education, less than tertiary & $2.39 *$ & $2.29 * *$ & 1.50 & 1.49 & 1.53 & 1.52 & 1.55 & 1.54 \\
\hline Paternal occupation, not professional/managerial & $2.26^{*}$ & $1.93 * * *$ & 1.20 & 1.17 & 1.14 & 1.12 & 1.12 & 1.12 \\
\hline Recurrent/protracted parental unemployment & $2.97 * *$ & $2.82 * * *$ & $2.36 * * *$ & $2.17 * * *$ & $2.03 * * *$ & $1.93 * *$ & $1.83 * *$ & $1.80 * *$ \\
\hline Retrospective perception of poverty & 2.09 & $2.20 * * *$ & & 1.48 & & 1.29 & & 1.11 \\
\hline
\end{tabular}




\begin{tabular}{|c|c|c|c|c|c|c|c|c|}
\hline & \multicolumn{8}{|c|}{ Estimated odds ratio for child maltreatment } \\
\hline & \multicolumn{2}{|c|}{ Unadjusted models } & \multicolumn{6}{|c|}{ Multivariate models } \\
\hline & $\begin{array}{c}\text { Complete } \\
\text { case }\end{array}$ & $\begin{array}{l}\text { Multiply } \\
\text { imputed }\end{array}$ & 1 & $1 \mathrm{a}$ & 2 & $2 \mathrm{a}$ & 3 & $3 \mathrm{a}$ \\
\hline Witnessing domestic violence, joint significance & & & $* * *$ & $* *$ & $* *$ & & $*$ & \\
\hline Lack of homeownership & 1.75 & $2.52 * *$ & 1.82 & 1.55 & 1.58 & 1.39 & 1.43 & 1.24 \\
\hline Maternal education, less than tertiary & $10.75^{* *}$ & $2.80 * * *$ & 1.50 & 1.53 & 1.48 & 1.52 & 1.37 & 1.42 \\
\hline Maternal occupation, not professional/managerial & $5.54 * *$ & $3.05 * *$ & 1.73 & 1.67 & 1.57 & 1.53 & 1.71 & 1.67 \\
\hline Paternal education, less than tertiary & $3.00 * *$ & $1.87 * *$ & 0.90 & 0.87 & 0.86 & 0.83 & 0.86 & 0.84 \\
\hline Paternal occupation, not professional/managerial & $6.37 * * *$ & $2.42 * * *$ & 1.70 & 1.60 & 1.59 & 1.52 & 1.56 & 1.49 \\
\hline Recurrent/protracted parental unemployment & $3.22 * * *$ & $2.95 * * *$ & $2.43 * * *$ & $2.00 * *$ & $2.12 * *$ & $1.82 *$ & $1.96 * *$ & $1.76^{*}$ \\
\hline Retrospective perception of poverty & $5.16^{* * *}$ & $3.34 * * *$ & & $2.36 * * *$ & & $2.11 * * *$ & & $1.95 * *$ \\
\hline \multicolumn{9}{|l|}{ Variables included: } \\
\hline Demographic characteristics & & & Yes & Yes & Yes & Yes & Yes & Yes \\
\hline Prospective childhood economic factors & & & Yes & Yes & Yes & Yes & Yes & Yes \\
\hline Perceived childhood poverty (retrospective) & & & & Yes & & Yes & & Yes \\
\hline Parental mental health and substance use & & & & & Yes & Yes & Yes & Yes \\
\hline Parental separation and prospective child health indicators & & & & & & & Yes & Yes \\
\hline Perceived childhood health (retrospective) & & & & & & & & Yes \\
\hline
\end{tabular}

$* \mathrm{p}<0.10 ; * * \mathrm{p}<0.05 ; * * * \mathrm{p}<0.01$. MI: multiply imputed

Model 1 includes only the first six economic factors listed in the table excluding retrospective poverty. Model 1a includes all seven economic factors (adds retrospective perception of poverty).

Model 2 includes first six economic factors and controls for demographic variables (father less than age $22 \mathrm{y}$, mother less than age $22 \mathrm{y}$, parental immigration from non-English-speaking countries, more than four children in family), and indicators of parental mental health and substance use (parental smoking, maternal drinking, paternal drinking, parental mental illness as reported by cohort members, and parental substance use problems as reported by cohort member). Model $2 \mathrm{a}$ adds retrospective perception of poverty.

Model 3 includes all model 2 variables plus parental separation and prospective measures of child health (low birth weight, and multiple investigated health problems by 3-4 years). Model 3a adds retrospective reports of poverty and child health (cognitive or behavioral problems, and physical health problems while growing up). Thus models 3 and 3 a include control variables with potential endogeneity to child maltreatment and may be conservative or 'overadjusted'. All multivariate models use multiple imputation for missing data. 
Table 7

Fractions of child maltreatment attributable to economic disadvantage.

\begin{tabular}{|c|c|c|c|c|c|c|c|}
\hline \multirow[b]{2}{*}{ Economic factor } & \multicolumn{7}{|c|}{ Population attributable fraction } \\
\hline & Any & $\begin{array}{c}\text { High- } \\
\text { intensity } \\
\text { emotional }\end{array}$ & $\begin{array}{c}\text { Low- } \\
\text { intensity } \\
\text { emotional }\end{array}$ & Neglect & Physical & Sexual & $\begin{array}{l}\text { Witnessed } \\
\text { Domestic } \\
\text { Violence }\end{array}$ \\
\hline \multicolumn{8}{|l|}{ Model 3} \\
\hline Lack of homeownership & $0.028 * *$ & 0.030 & 0.028 & 0.006 & 0.067 & 0.068 & 0.046 \\
\hline Maternal education, less than tertiary & 0.111 & 0.150 & 0.216 & 0.224 & -0.262 & 0.106 & 0.197 \\
\hline Maternal occupation, not professional/managerial & -0.058 & 0.049 & -0.148 & -0.068 & -0.254 & 0.118 & 0.312 \\
\hline Paternal education, less than tertiary & -0.008 & -0.122 & -0.061 & -0.078 & -0.002 & 0.245 & -0.092 \\
\hline Paternal occupation, not professional/managerial & 0.057 & 0.034 & 0.005 & -0.041 & $0.474 * * *$ & 0.062 & 0.230 \\
\hline Recurrent/protracted parental unemployment & $0.118^{* * *}$ & $0.204 *$ & $0.136^{*}$ & 0.137 & 0.178 & $0.223 * *$ & $0.251 *$ \\
\hline Retrospective perception of poverty & - & - & - & - & - & - & - \\
\hline All economic factors & $0.245^{* * *}$ & 0.326 & 0.199 & 0.207 & $0.356^{* *}$ & $0.614 * * *$ & $0.688 * *$ \\
\hline \multicolumn{8}{|l|}{ Model $3 a$} \\
\hline Lack of homeownership & 0.020 & 0.015 & 0.017 & -0.009 & 0.046 & 0.062 & 0.031 \\
\hline Maternal education, less than tertiary & 0.106 & 0.147 & 0.208 & 0.201 & -0.240 & 0.089 & 0.207 \\
\hline Maternal occupation, not professional/managerial & -0.056 & 0.044 & -0.143 & -0.049 & -0.283 & 0.127 & 0.290 \\
\hline Paternal education, less than tertiary & -0.018 & -0.137 & -0.075 & -0.092 & -0.028 & 0.237 & -0.106 \\
\hline Paternal occupation, not professional/managerial & 0.043 & 0.010 & -0.014 & -0.057 & $0.449 * *$ & 0.060 & 0.199 \\
\hline Recurrent/protracted parental unemployment & $0.093 * *$ & 0.165 & 0.103 & 0.092 & 0.103 & $0.213^{*}$ & 0.212 \\
\hline Retrospective perception of poverty & $0.087 * * *$ & 0.171 & $0.125 * *$ & 0.151 & $0.302 * * *$ & 0.028 & $0.180 * *$ \\
\hline All economic factors & $0.273^{* * *}$ & 0.375 & $0.237^{*}$ & 0.252 & $0.454 * *$ & $0.612 * * *$ & $0.714 * * *$ \\
\hline
\end{tabular}

$* \mathrm{p}<0.10 ; * * \mathrm{p}<0.05 ; * * * \mathrm{p}<0.01, H_{0}: \mathrm{PAF}=0$

Model 3 estimates are adjusted for all prospective economic factors, all demographic factors (father less than age 22 years, mother less than age 22 years,

parental immigration from non-English-speaking countries, more than four children in family, parental separation); all indicators of parental mental health and substance use (parental smoking, maternal drinking, paternal drinking, parental mental illness as reported by cohort members, and parental substance use problems as reported by cohort member); and all prospective indicators of child health (low birth weight, multiple investigated health problems by $3-4$ years). Model $3 \mathrm{a}$ is additionally adjusted for retrospective perception of poverty, retrospective reports of cognitive or behavioral problems while growing up, and retrospective report of physical health problems while growing up. All estimates are multiply imputed. As risk factors overlap, estimates cannot be summed and the estimates for all economic factors are less than the sum of their parts. 
Anpendix A -Economic risk factors for child maltreatment: Fine categories
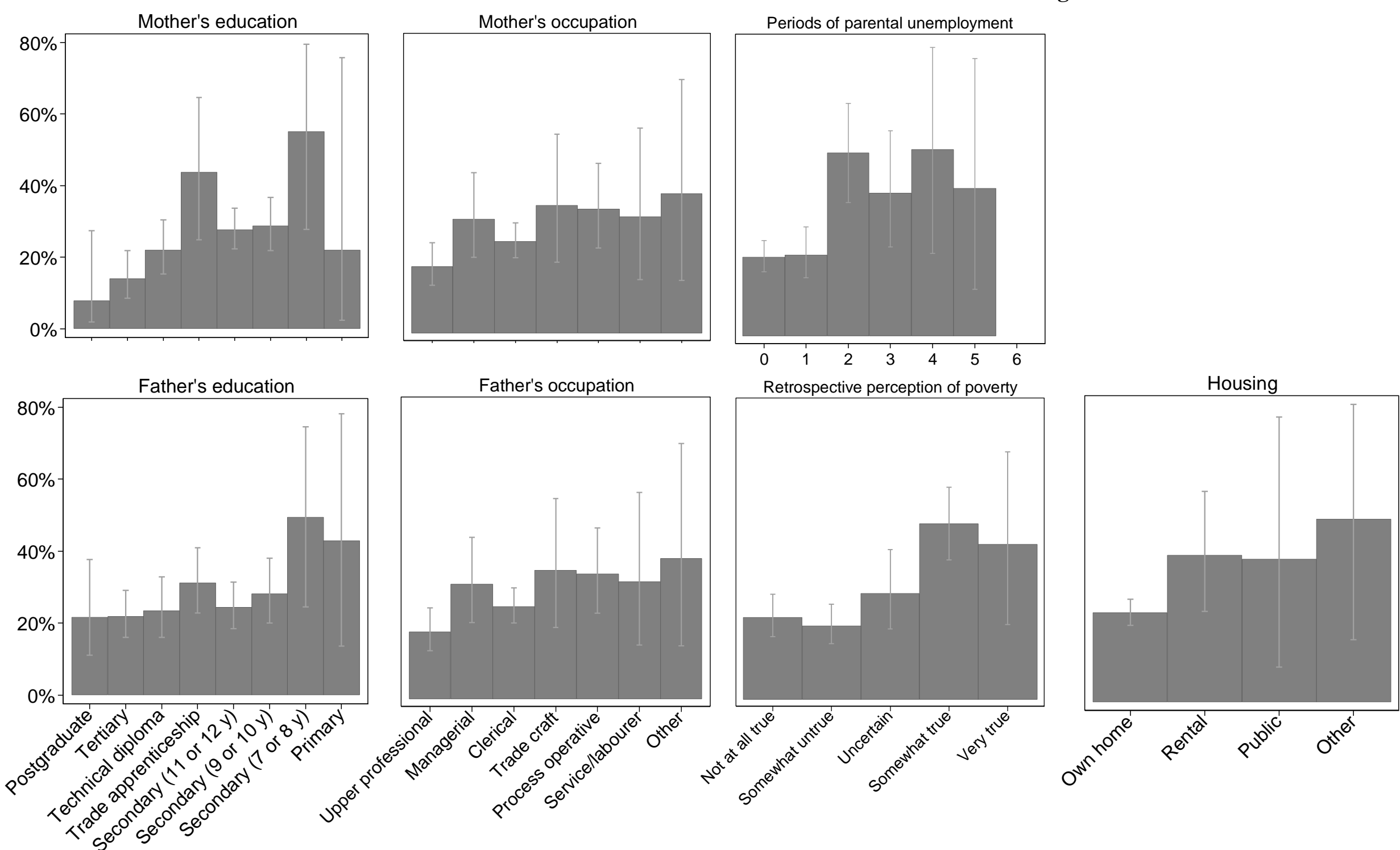

Fig. A1. Economic risk factors for child maltreatment: Fine categories

Prevalence of any child maltreatment (emotional, physical, or sexual abuse, neglect, or witnessing of domestic violence) by level of specific economic risk factors (parental education and occupation at 4-8 months [baseline], housing at 7-8 years [Wave 6], at least 2/10 points of parental unemployment between age 8 and 16 [Waves 7-11], and cohort members' retrospective perception of poverty during childhood at age 23-24 years [Wave 14]), prior to collapsing and multiple imputation of variables. 
Appendix B - Subtypes of sexual abuse or assault

Table B1

Regression models by subtype of sexual abuse or assault.

\begin{tabular}{|c|c|c|c|c|c|c|c|c|}
\hline \multirow[b]{3}{*}{ Economic factor, by child maltreatment outcome } & \multicolumn{8}{|c|}{ Estimated odds ratio for child maltreatment } \\
\hline & \multicolumn{2}{|c|}{ Unadjusted models } & \multicolumn{6}{|c|}{ Multivariate models } \\
\hline & $\begin{array}{c}\text { Complete } \\
\text { case }\end{array}$ & $\begin{array}{l}\text { Multiply } \\
\text { imputed }\end{array}$ & 1 & $1 \mathrm{a}$ & 2 & $2 a$ & 3 & $3 a$ \\
\hline Familial sexual abuse, joint significance & & & $* *$ & & & & & \\
\hline Lack of homeownership & 2.87 & $2.49^{*}$ & 1.89 & 1.72 & 1.59 & 1.50 & 1.47 & 1.43 \\
\hline Maternal education, less than tertiary & 1.87 & $2.47^{* *}$ & 1.47 & 1.48 & 1.48 & 1.49 & 1.36 & 1.36 \\
\hline Maternal occupation, not professional/managerial & 3.37 & $2.33^{* *}$ & 1.42 & 1.39 & 1.31 & 1.31 & 1.37 & 1.37 \\
\hline Paternal education, less than tertiary & 2.48 & $2.13^{* *}$ & 1.50 & 1.48 & 1.50 & 1.49 & 1.52 & 1.52 \\
\hline Paternal occupation, not professional/managerial & 1.83 & $1.61^{*}$ & 0.97 & 0.94 & 0.88 & 0.86 & 0.85 & 0.84 \\
\hline Recurrent/protracted parental unemployment & 2.25 & $2.29 * * *$ & $1.92^{* *}$ & $1.73 *$ & 1.60 & 1.50 & 1.39 & 1.35 \\
\hline Retrospective perception of poverty & 1.52 & $2.20 * * *$ & & 1.55 & & 1.35 & & 1.15 \\
\hline Nonfamilial sexual abuse or assault, joint significance & & & $* * *$ & $* * *$ & $*$ & $*$ & & \\
\hline Lack of homeownership & 1.81 & $3.58 * * *$ & $2.64 * *$ & $2.51^{* *}$ & $2.64^{*}$ & $2.63^{*}$ & $2.60^{*}$ & $2.62 *$ \\
\hline Maternal education, less than tertiary & 2.10 & $2.11 *$ & 1.28 & 1.27 & 1.37 & 1.37 & 1.28 & 1.27 \\
\hline Maternal occupation, not professional/managerial & 2.31 & $2.06 * *$ & 1.24 & 1.23 & 1.22 & 1.22 & 1.25 & 1.26 \\
\hline Paternal education, less than tertiary & 2.78 & $1.93^{*}$ & 1.22 & 1.21 & 1.23 & 1.22 & 1.25 & 1.24 \\
\hline Paternal occupation, not professional/managerial & 2.44 & $1.80^{*}$ & 1.17 & 1.15 & 1.15 & 1.15 & 1.17 & 1.18 \\
\hline Recurrent/protracted parental unemployment & $4.10 * *$ & $3.44 * * *$ & $2.83 * *$ & $2.67^{* *}$ & $2.36^{* *}$ & $2.33^{*}$ & $2.29 *$ & $2.29 *$ \\
\hline Retrospective perception of poverty & 2.30 & $2.21 * *$ & & 1.30 & & 1.06 & & 1.00 \\
\hline
\end{tabular}

$* \mathrm{p}<0.10 ; * * \mathrm{p}<0.05 ; * * * \mathrm{p}<0.01$.

Model 1 includes only the first six economic factors listed in the table excluding retrospective poverty. Model 1a includes all seven economic factors (adds retrospective perception of poverty).

Model 2 includes first six economic factors and controls for demographic variables (father less than age $22 \mathrm{y}$, mother less than age $22 \mathrm{y}$, parental immigration from non-English-speaking countries, more than four children in family), and indicators of parental mental health and substance use (parental smoking, maternal drinking, paternal drinking, parental mental illness as reported by cohort members, and parental substance use problems as reported by cohort member). Model 2a adds retrospective perception of poverty.

Model 3 includes all model 2 variables plus parental separation and prospective measures of child health (low birth weight, and multiple investigated health problems by 3-4 years). Model 3 a adds retrospective reports of poverty and child health (cognitive or behavioral problems, and physical health problems while growing up). Thus models 3 and 3 a include control variables with potential endogeneity to child maltreatment and may be conservative or 'overadjusted.'

All multivariate models use multiple imputation for missing data. 


\section{Appendix B - Subtypes of sexual abuse or assault}

Table B2

Population attributable fractions by subtype of sexual abuse or assault.

\begin{tabular}{lcc}
\hline & \multicolumn{2}{c}{ Population attributable fraction } \\
\cline { 2 - 3 } Economic factor & Familial sexual abuse & $\begin{array}{c}\text { Nonfamilial } \\
\text { sexual abuse or assault }\end{array}$ \\
\hline Lack of homeownership & 0.046 & 0.124 \\
Maternal education, less than tertiary & 0.183 & 0.150 \\
Maternal occupation, not professional/managerial & 0.185 & 0.139 \\
Paternal education, less than tertiary & 0.231 & 0.128 \\
Paternal occupation, not professional/managerial & -0.083 & 0.091 \\
Recurrent/protracted parental unemployment & 0.117 & 0.311 \\
Retrospective perception of poverty & 0.038 & 0.005 \\
All economic factors & $0.570 * *$ & $0.679 * *$
\end{tabular}

${ }^{*} \mathrm{p}<0.10 ;{ }^{* *} \mathrm{p}<0.05 ; * * * \mathrm{p}<0.01, H_{0}:$ PAF $=0$

Estimates based on model $3 a$ in Table 3 (adjusted for all economic factors, all demographic factors [father less than age $22 \mathrm{y}$, mother less than age $22 \mathrm{y}$, parental immigration from non-English-speaking countries, more than four children in family, parental separation]; all indicators of parental mental health and substance use [parental smoking, maternal drinking, paternal drinking, parental mental illness as reported by cohort members and parental substance use problems as reported by cohort member]; and all indicators of child health [low birth weight, multiple investigated health problems by 3-4 years, retrospective reports of cognitive or behavioral problems, and physical health problems, while growing up]). As risk factors overlap, estimates cannot be summed and the estimate for all economic factors is less than the sum of its parts. 